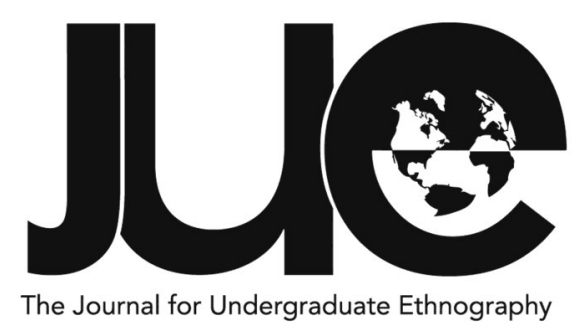

\title{
The New Normal in Urban Pakistan: A Journey of Undergraduate Students Through Photovoice
}

\author{
Authors: Muhammad H. Raza (mr05189@st.habib.ed.pk), Neha Khatri \\ (nk03590@st.habib.edu.pk), Sara Intikhab (si04515@st.habib.edu.pk), \\ and Rumaysa Iqbal (ri05126@st.habib.edu.pk), Habib University \\ Contributors: Azka Rehman, Areeb A. Khowaja, Mishal B. Khan, \\ Morsche Qhan, Muhammad A. Yousuf, Muhammad O. Chowdri and \\ Nabeel Lal , Habib University
}

\section{ABSTRACT}

The COVID-19 global health crisis is an issue of survival for individuals and communities worldwide. With its widespread consequences manifested at every level of the society, concerns about how to adapt to the new normal are rising. This study explores the lived experiences of second-year undergraduate university students located in urban Pakistan amid the early months of the COVID-19 pandemic, in March to May 2020. Drawing on a participatory research approach, students as participants adopted a photovoice methodology to document, share, and analyze their new life realities. The themes that emerged from the data include fear, anxiety, isolation, relationships and hope, among others. Feelings of agency, empathy and a desire for community action were observed in the photo narratives shared by the participants, as they discussed their health, academic, and communication challenges while struggling to conform to the present circumstances.

Keywords: students; COVID-19; urban Pakistan; participatory research; photovoice 
$\mathrm{O}$ $\mathrm{n}$ January 22nd, the World Health Organization (WHO) issued a statement saying that there is evidence of human transmission of a viral disease with further investigation required to measure its extent. The same month, the WHO Director-General had declared the novel coronavirus outbreak a Public Health Emergency of International Concern (PHAIC). The pandemic has overwhelmed health-services around the globe, with the number of patients requiring critical care surging with every passing day (O'Reilly et al. 2020, 1). However, the virus has not only severely impacted its hosts but also the lives of every person surviving the outbreak. The world has come to the brink of a historically unprecedented halt and has seen and captured moments which may serve as a defining representation of this pandemic. Images of empty shelves in the grocery stores and long queues outside supermarkets have been the usual sight even before the imposition of lockdown in many countries. Although the production levels and stocks for staple food are at an all-time high, the issue of hunger is looming over millions of households globally, due to businesses shutting down, mass layoffs, and disruptions in domestic supply chains (Voegele 2020). Furthermore, increased media reporting and an escalating number of deaths coupled with curfews and lockdowns have led to increased psychological problems including anxiety, stress, and depression (Lima et al. 2020, 1-2).

With the many marks that the pandemic has left on every walk of human life, the education sector has also been affected globally (Burgess and Sievertsen 2020). During the closure of schools and universities in many parts of the world, curriculums have been altered to adapt to online channels for distance learning.
However, this shift has raised many concerns regarding the inaccessibility of modern technology to many students if not all, thus seriously damaging the basic uniformity in their educational experience (LeBlanc 2020).

On February 26th, the government of Pakistan confirmed the first case of COVID-19 in Karachi. Soon the schools, followed by colleges and universities, were shut down in the province of Sindh, where our university is located; this was an instant decision taken by the provincial government to contain the virus. The initial announcement was for a closure of two weeks, however, it kept on extending as the number of cases and the death toll increased. With the lockdown imposed in most parts of the country and the university curriculums shifted online, students were expected to adapt to the new normal.

The online transition from traditional inperson classes to online classes has not been smooth in Pakistan and is particularly affecting students from remote and low-income areas (Ali 2020). These challenges vary from lack of acceptance of online learning, to a general suspicion amongst elders regarding the usage of gadgets, to a shortage of individual study spaces. This list is not inclusive of the technical challenges faced by the students such as connectivity and bandwidth issues; only onethird of the Pakistani population had a broadband subscription by the end of 2019 (Rehman 2020). The number for 3G/4G subscription was similar. Ali (2020) reports a story of a Baloch student who began an online campaign raising awareness about the digital divide in Pakistan and demanding that online classes halt and students be given a semester break. However, a positive outcome of COVID19 is that it is pushing the Pakistani educational ministry to repair and revamp their system (Siddiqi 2020).

Our study aimed to document the ways in which university students were acclimatizing to the conditions they had never faced before. Photovoice, as one method of participatory action research (PAR), has been widely used to better understand realities at local and community levels. It involves research participants taking photographs which are combined with their individual stories in 
response to a research question. The group then discusses the pictures, what they present, and how they answer the concerned question through an individual perspective. Lastly, a final selection of the photographs based on the messages and insights the group wishes to project exhibits the answer of the participants collectively. Thus, photovoice is not an individual's story, rather it is a group's message.

This study uses photovoice to examine the life online of undergraduate university students in urban Pakistan. It presents the challenges, coping mechanisms, personal sentiments, and reactions to the drastic changes in student and social life due to the novel coronavirus pandemic. In doing so it explores the lived experiences of undergraduate students amid an uncommon global crisis, specifically focusing on the regional, social, educational, and familial context of the participants involved.

The article presents a review of the literature on the method used for this study, the impact of the pandemic on students, and their experience with online learning. It then discusses PAR as the chosen methodology and its significance to the participants, followed by a thematic analysis of the primary data. It concludes with the study findings, identifying potential avenues for future research and highlighting the pedagogical value of the study and its policy implications.

\section{Photovoice as a participatory method}

The photovoice method, is a participatory process through which individuals are entrusted with camera to create visual images that may reflect, enhance, and represent their environments. The goal of such a method is to center the individual's own experience, and to build critical dialogue around it (Wang and Burris 1997, 369). Thus, we were exploring what it means to live through a lockdown in terms of emotive, photographic evidence. To gauge the effectiveness of this method, we reviewed research-based studies that adopted photovoice to gather data and interpret evidence. The review also includes controlled and mixed methods studies assessing the impact of online learning on students' stress levels, but our focus is on the lived experience of individuals and how it shapes their realities.

One such study conducted by Tedrick Parikh and Wachter Morris $(2011,2)$ showed that students cope more agreeably with a crisis when they have outlets of intervention at hand. Similarly, according to a study by Dattilio and Freeman $(2007,3)$ students' responses to crises depend on the meaning they place upon the situation. Thus, with this, we reinforce our thesis and the idea that personal reflection through documentation i.e., a method such as the photovoice, allows students to subsist through hardship more effectively.

In another study, Shortt, Rhynas, and Holloway (2017, 7) used a photovoice methodology to understand the experience and perceptions of the role of the environment in recovery from alcohol dependence. The participatory research approach helped to capture the perspective of the participants with as few errors as possible in the contextual analysis of the data while reshuffling the traditional researcher-participant power relation. This study further lends credence to the photovoice methodology, asserting that such a method allows groups, especially vulnerable groups, to become stakeholders in their narrative.

A study conducted in Beirut, Lebanon by Strack, Magill, and McDonagh $(2004,8)$ used photovoice as a PAR method to promote health awareness amongst youth. The study aimed to adopt this method specifically to adolescents, to test its effectiveness, and to replicate it for further studies. The study concludes that the photovoice method encourages empowerment amongst the participants. It also signified that this process allowed youth a better understanding of their environment and a desire to engage in community work. Similarly, another study using photovoice in Los Angeles, California, concluded that photovoice projects help youth identify and engage with elements that may be causing emotional disarray that they previously could not place before documentation (Necheles et al. 2007, 9). However, despite the array of positive feedback concerning this method, it does have limitations. According to Strack, Magill, and McDonagh $(2004,9)$, projects like this must be 
tailored specifically to its participants. It requires vigorous site selection, curriculum planning, and participant recruitment. Similarly, another such study asserts that such methods can be time-consuming, costly, and laden with ethical concerns of consent and risk for participants. Thus, when applying this methodology, it is essential to adapt to these challenges.

\section{The impact of COVID-19 on students}

There is limited literature available on the current crisis, particularly investigating its impacts on the lives of the population. Pan $(2020,2)$ studied the family life of students in Xiamen city, China amidst the COVID-19 pandemic. The data gathered from online surveys showed an increase in time spent by the students watching television, reading books, and playing video games. Around 15 percent of the participants started to care more for their personal hygiene due to time availability. Overall, the paper presented basic statistical data collected from an unrepresentative sample drawing little evidence-based analysis. The pandemic also reflects social inequalities present in our society. Franco (2020, par. 6) highlights the lower allocation of resources to study 'social inequalities by neighborhood and urban health' compared to the other fields of concern. This has resulted in poor housing quality, making it difficult for the citizens to survive in crises such as the current pandemic where one is strictly confined to their living spaces.

A global pandemic is naturally coupled with psychological problems such as stress, anxiety, and post-traumatic disorders. These complications can be due to the existence of general uncertainty, loss of jobs, and decreased income. However, students may suffer from similar complications because of a sudden and massive shift to their learning experience, which in some cases has manifested in a complete educational pause or moving online in others. Jung, Kudo, and Choi $(2012,2)$ in a study conducted in Japan, sampling 226 students taking English-based online courses, identified four factors influencing stress: selfefficacy, instructional design, technology use, and collaborative process. The study reveals that a limited understanding of using information and communication technology as an interactive educational medium alone may result in "negative attitudes, thoughts, and behaviors" (Choi 2012, 2). Lazarevic and Bentz (2020, 10-11) conducted a study that aimed to find out whether there was a difference in the stress levels when students were given instructions in the traditional face-to-face way and an online setting. The data collected from the web-based survey represented differed stress levels between the two groups: online and traditional face-to-face learning. Interestingly, the stress levels were significantly lower in the students who were learning in an online-based setting as opposed to traditional. However, none of the studies took into account factors such as the effects of reduced in-person interactions of the participants with their friends or classmates and confinement to their homes. Dana Goldstein, Adam Popescu, and Nikole Hannah-Jones (2020, par. 19-20) outline the difficulties faced by educators in the rural United States due to lower class participation and raising absenteeism as the school curriculums shifted online during this crisis. The emerging reasons behind this are rooted in limited adult supervision, uneven levels of technology, and broader economic and health effects of the outbreak.

Since this pandemic is a recent global occurrence, we observe a significant gap in the existing literature on how it has affected the lives of those surviving it, particularly students. The studies based on the coronavirus outbreak, so far, revolve around its medical aspects and not its social implications. Any crisis triggers an emotional, physiological, cognitive, and behavioral response (Bergh 2009, 5) and our study aim to document these responses in the current situation through photovoice. This research helps in building literature on the social impact of the pandemic, since there are only a handful, small scale studies covering the pandemic's impact on a community level.

\section{Methods}

Participatory Action Research, or PAR, is a strand of critical action research in which the participants of a study are assigned the roles of 
co-researchers (Duncan-Andrade and Morrell 2008). Although the co-researchers are mostly drawn from marginalized groups, the case is not inherently consistent throughout. In traditional research, participants are seen as objects (Duncan-Andrade and Morrell 2008) while PAR adopts a social justice orientation giving them a real voice by recognizing their agency. This methodology is of particular importance when it comes to students in Pakistan. Student unions have been banned since 1984 across the country and the authorities do not recognize student rights, thus students as a group have been effectively disempowered for more than three decades. This marginalization of students has further led to an existential crisis of political leadership in Pakistan (Rashid 2019). The study thus uses a PAR method, photovoice, at least partly in order to highlight research as a source of advocacy for students and other alienated groups while emphasizing participation and dialogue.

Photovoice is a method that enables to document the lives of the participants in the form of visual representation as they conceptualize their reality. It is theoretically grounded in Paulo Freire's Education for Critical Consciousness (1974) and Pedagogy of the Oppressed (1970) as he approaches education for critical consciousness, maintaining that visualization is a significant tool of reflection on one's community (Ronzi et al. 2016, 3) and highlights the need to take action against the repressive elements. PAR methods such as the one employed in this study are widely used in public health and educational research. Their reliance on participants' knowledge to better understand the issues makes them unique among other qualitative approaches.

The study was conducted as part of an undergraduate course, an introduction to qualitative research in which the students used the photovoice method in an assignment posted during the second week of off-campus learning. Each student was instructed to capture multiple photographs representing different themes of their online educational and social experience and their life amidst the pandemic. All used their own cameras to capture the photographs and were given the options of realistic, staged, or symbolic as well as collage images to convey their message, as per their personal preference. The photographs were supposed to be coupled with narratives describing the image, which included the meaning participants had derived from them and how the images responded to the research prompt. This was followed by each participant giving a presentation on ten selected images supplemented by class discussion and reviews from the rest of the target group members.

The participants were the students enrolled in the course: six women and five men. All were in the sophomore year of their undergraduate degree at the time of the study. They were aware of the PAR approach and willingly opted to conduct a study using the photovoice method. Informed consent was taken from all the participants of the study to use the pictures from their collection as the data source. The selection of the images was conducted by a consensual decision taken by the participants. The final draft of the research paper was also sent to the members of the target group for review before its submission to the journal.

\section{From Fear to Boredom to Hope in Students" Photos}

The data for this study include 120 photographs and their captions. Data analysis proceeded as follows. The images were categorized into ten different themes, based on what visually emerged from them and their deeper meaning indicated through the captions coupled with a focused group discussion. There had to be at least two photographs explaining similar aspects for a theme to be formed. However, on average each theme had five or six photographs contained within it. A thematic content analysis was then conducted of all the collected data. As photovoice was a new method for most of us, it took us some time to accustom ourselves to convey ideas through photographs. However, once we got across that stage, the process became much smoother and meaningful and we found our ideas flowed well.

Multiple themes thus emerged from the photographs presented by the participants. During an in-class meeting, the most preferred themes were selected for the thematic analysis. Students shared the themes that they thought emerged from the photographs through the 
chat option on Microsoft Teams, which was followed by filling a ranking priority category document prepared by our professor where each of us wrote down our five preferred themes, by our names. Once we started working on the thematic analysis, we re-visited the selection of the themes and added a few new themes based on further communication with the participants. A focus group discussion was replicated online, though it had shortcomings mostly due to connection issues. However, under the current circumstances that was the only medium of interaction available, and while it was not ideal, it was useful, as we did end up adding two more themes and having a more in-depth understanding of what meaning the participants wanted to present as a group through the photographs.

Going through the photographs of our classmates in class and seeing how the lockdown had been affecting them was an extremely personal and intimate experience. In most of our courses, we do not get to interact at such a personal level, but studying qualitative research allowed us to interact with each other at a much deeper level.

Although the thematic analysis is drawn from all the images that our participants captured, we have presented only two or three of them with each theme, based on the consensual decision taken by participants. The themes below range from many different aspects of the lockdown, from student specific experiences to broader aspects such as health and relationships. We present a brief description of each theme followed by an analysis of what the participants presented through their photographs.

\section{Lockdown}

The contagiousness and novelty of this pandemic has resulted in the application of preventative measures, until a vaccine is developed. The most salient of these measures is social distancing, enforced nationwide with the help of a lockdown. Unused to the quietness now reigning over the busiest city in Pakistan, some students illustrated this emptiness through their photographs.

According to Rose-Redwood et al. $(2020,8)$, the novel quietness creates a rhetoric of "telling the story of the pandemic", and this sudden deurbanization will affect the way we think about mobility, relations, and social practices. Karachi is "one the fastest growing megacity in the world" (The Urban Resource Centre, Karachi, Hasan, and Raza 2015, 5) and the most diversely populated city of Pakistan with people from various cultures residing together. It is also the economic hub of Pakistan as it is a coastal city with ports. All this combined makes Karachi a remarkably busy city which is always awake. To see such a city empty, especially in busy spots of the city such as Dhoraji (see Figure 1) and the old Clifton Bridge, was strange to witness for participants (see Figure 2). One of the participants mentioned that the silence was almost scary since there was no activity or sign of social interaction outside. Apart from the looming silence, like most places, Pakistan has formulated regulations that need to be

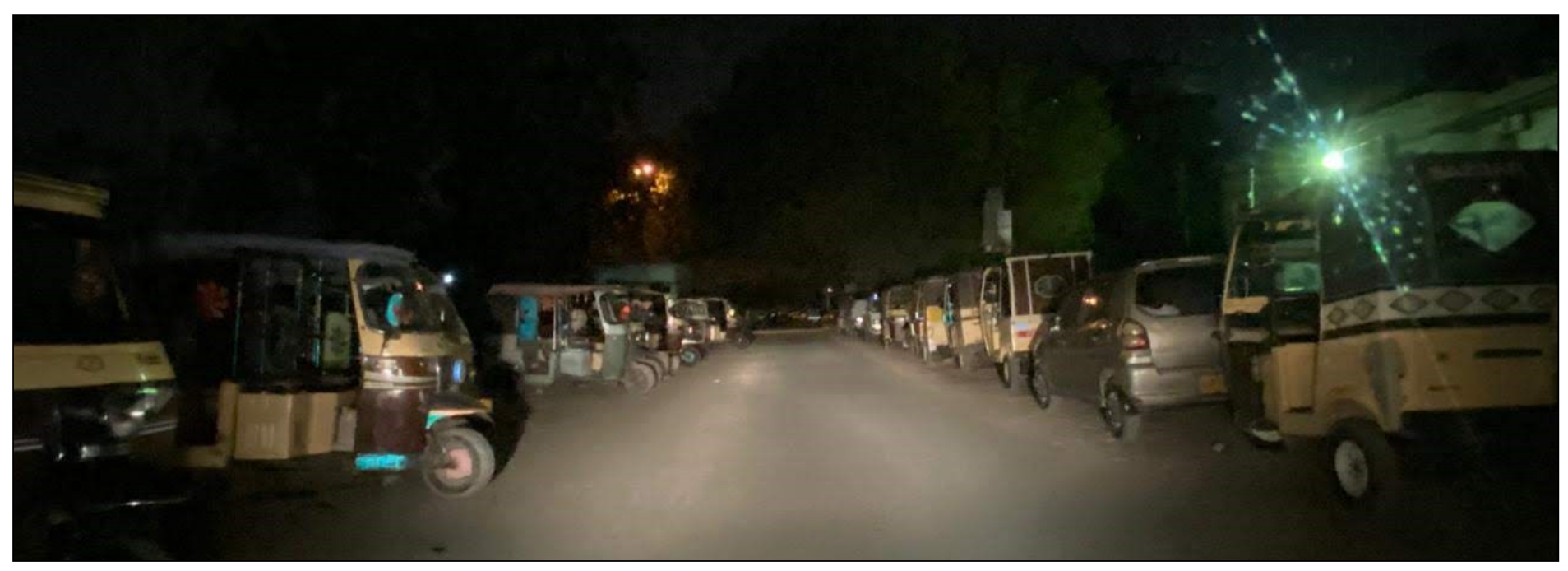

Figure 1. A rikshaw-stand during what would have been peak hours in a pre-pandemic world. - Aqib 


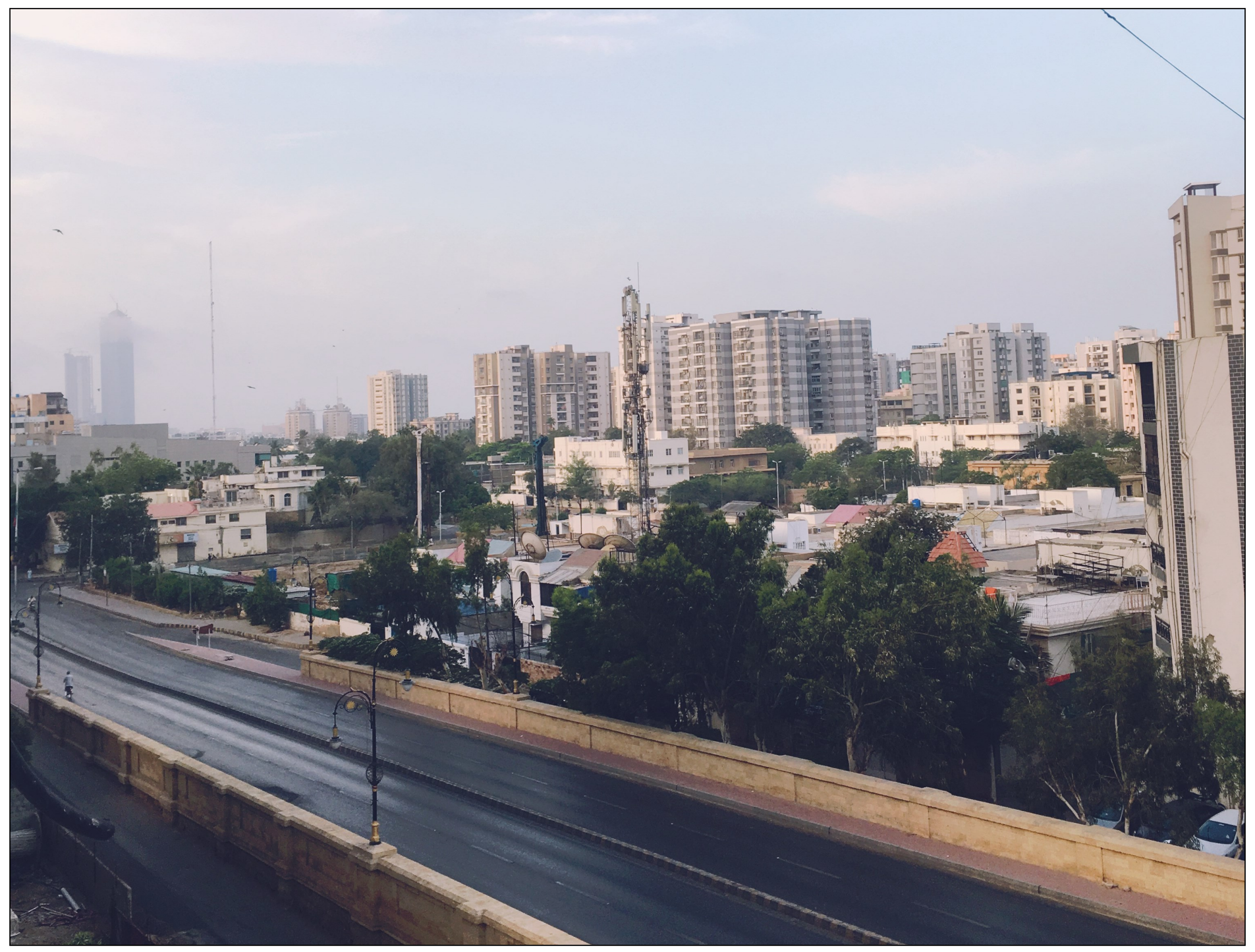

Figure 2. The once hustling bustling Clifton Bridge. Normally this bridge is overflowing with vehicles and my home is filled with noisy traffic sounds. My family and I are so used to hearing them that we didn't realize just how loud these sounds were until a lockdown was in place. Now, one would expect to find peace and calmness with all the noise pollution brought to a bare minimum, but that's not the case. In fact, it has created such a depressing and gloomy atmosphere, given the situation that we are all in. The silence is kind of scary and serves as a reminder that we are living in a very different world, yet we are trying to continue life as usual. For me, as a student it's continuing to study - except that it is online now. - Neha

followed in public spaces due. A participant highlighted the 'six-feet' distance strategy being implemented outside a shop which had marked circles at a 'six-feet' distance.

\section{Trapped and isolated}

The most insidious aspect of an enforced lockdown with social distancing and the abrupt closure of community spaces is its effect on psychological health. Research studies on previous pandemics such as the SARS pandemic have highlighted that ten per cent of non-affected and up to 70 per cent of affected populations developed various stress triggers and mood disorders (Taylor and Asmundson 2020, 2).

This feeling of isolation emerged as a potent theme once we analyzed the pictures submitted by the students. The closure of community spaces, such as religious centres, mosques, 


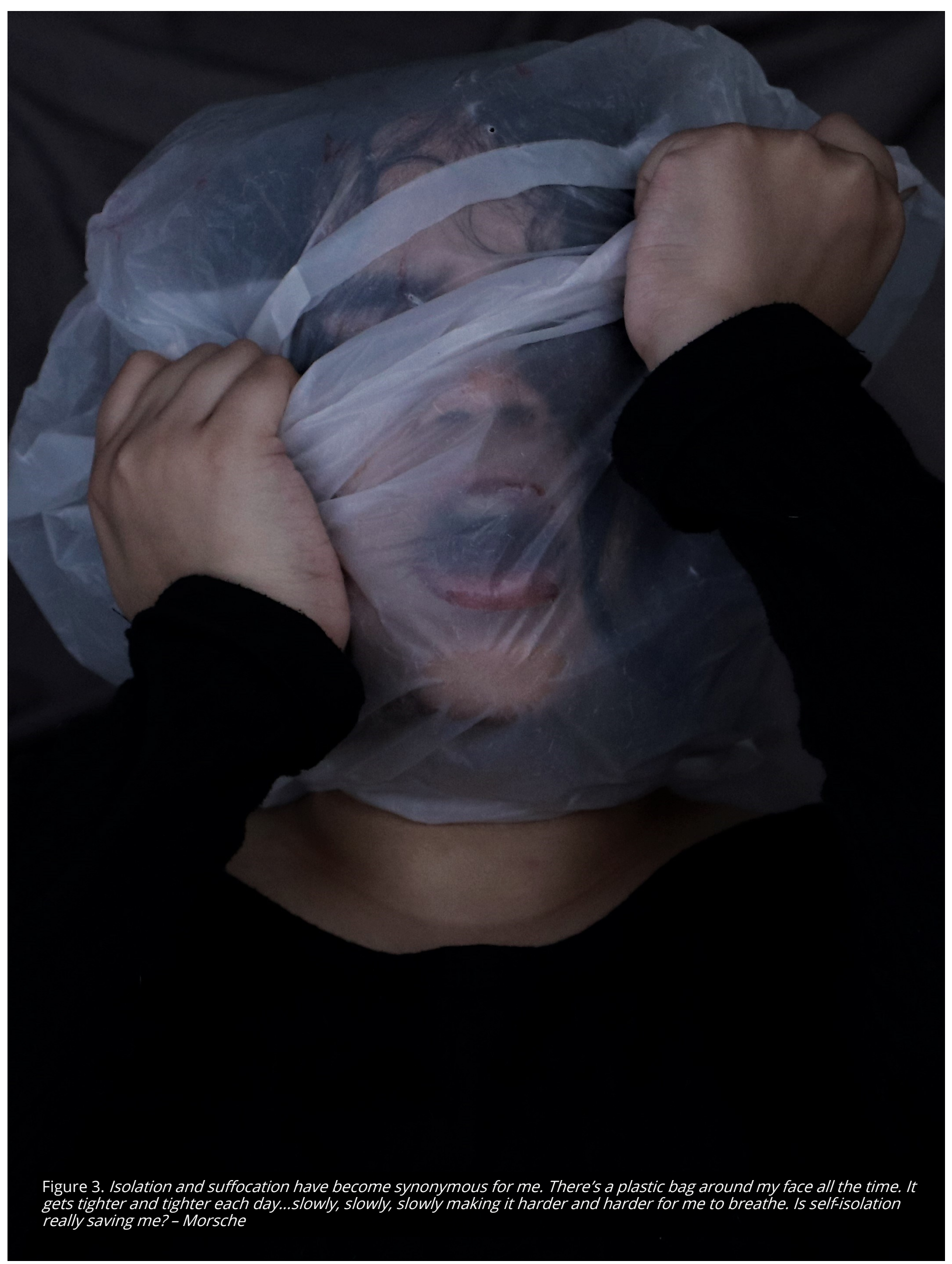


libraries, cultural centers, weekly mushairas (poetic symposium), and also the loss of routine interactions at university led to an increased feeling of loneliness among students (Banerjee and Rai 2020). To portray this element of 'feeling trapped' and 'loneliness,' the participants overwhelmingly used the symbol of window grilles (see Figure 4). This highlighted the separation of the inside world from the outside world and the way it has now become inaccessible. That being said, one participant did use window grilles in their photo with an optimistic narrative, showing the clean air outside rather than showing the emotion of feeling 'trapped' - which was meant to be left unsaid. There was also the emotion of 'longing' for the outside world that resonated across many of the photographs. Another participant showed this emotion by staging a photograph of herself being suffocated with a plastic bag (see Figure 3). The strong visuals of the image portrayed how destructive self-isolation could be. Overall, the images used some sort of a barrier between them and what they wanted to reach out for, which was observed as a lack of freedom and physical interaction.

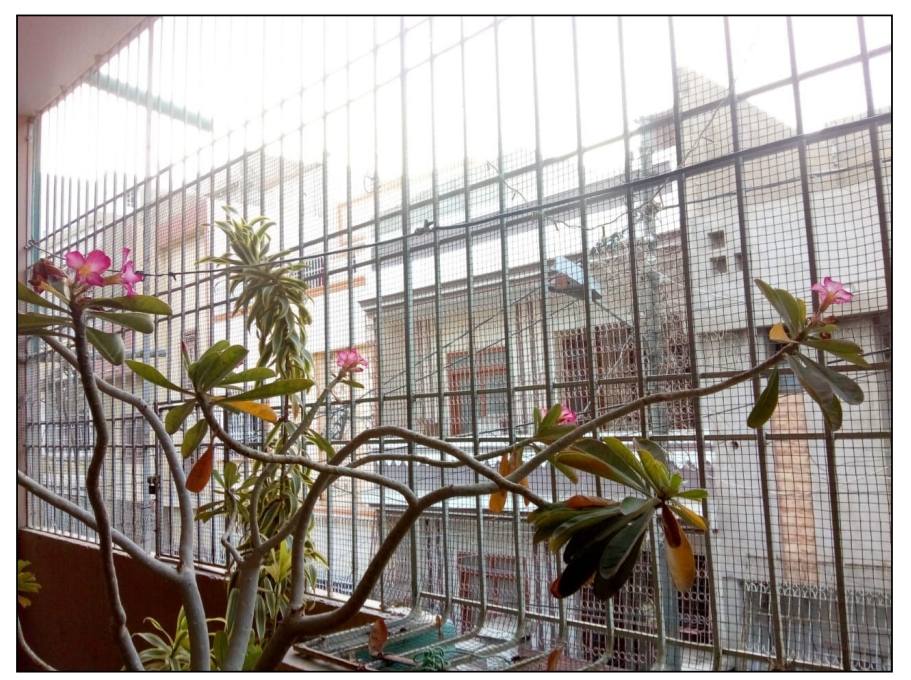

Figure 4. Caged. There is no window in my room and the terrace is completely packed too [packed implying that the view outside is blocked by window grilles and is restricted to the small square openings only]. I haven't been out (AT ALL) since last 4weeks. Makes me feel caged and suffocated. - Azka

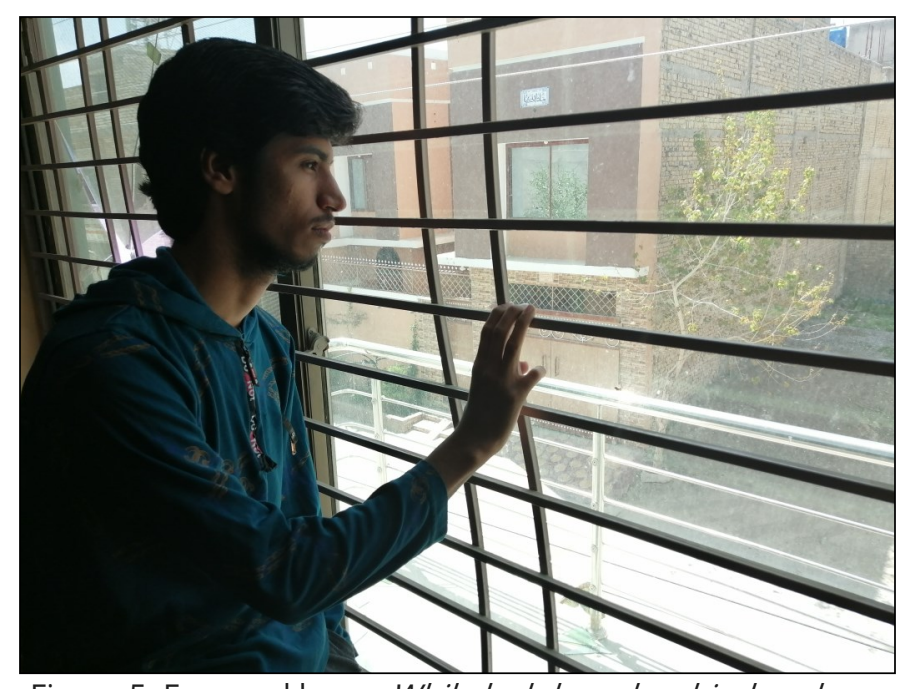

Figure 5. Fear and hope. While lockdown has hindered every social and economic life, for some students looking out through their windows is the only way to escape the harsh reality that world is going through. This picture depicts hope and fear at same time; fear because despite our deep desire to go out and have fun, one simply cannot, and a hope because with every possible human effort to curb down this pandemic, one starts picturing people in the empty streets.

Shut, locked and standing behind the bars,

I wonder if I am prisoner war.

But I don't see streets with blood,

And hands with guns,

Then why is our world so shunned?

I hear people are dying

From a virus unknown.

I stand next to my window,

And wait for a new dawn.

Scared, worried, and the peace of mind is long gone. - Nabeel

\section{Health and Safety}

Another theme that emerged through this study, was the increased hyper vigilance and paranoia surrounding students' own health and the health of their loved ones. This fear has its basis in the contagious nature of the virus, which could manifest exponentially in participants with already existing illnesses and diseases. One study (Taylor and Asmundson 2020) has concluded that during the current pandemic people have developed a Covid Stress Syndrome. This entails a fear of infection, touching surfaces, contamination and even xenophobia. Similarly it is also concluded that the pandemic may cause an increase in agoraphobia (Taylor and Asmundson 2020, 2).For many students, there has been an increased focus on ensuring protection against the virus by making their immune system stronger. Pre-existing illnesses are also resurfacing as issues of primary concern for parents and patients alike, so that they can be kept under control by ensuring regular 
medicine intake and adopting all necessary precautions (see Figure 6). This may mean that the participant has to take more medicines than they would normally have to.

Precautions against the virus have also become essential parts of the participants' lives now, which are slowly becoming normalized and adopted into their regular routines. The most common symbol used to shed light on this matter was hand sanitizer (see Figure 7). Two other photographs also included face masks, which have also become symbolic of pandemics in the past such as the Spanish flu pandemic of 1918-1920. One participant chose to highlight the theme of health and safety in a unique way by showing four fresh towels hanging, each meant for a specific person of the family. This aligns with the concept of taking maximum hygienic precautions during the pandemic. It was also meant to highlight a sense of fear that existed within the house.

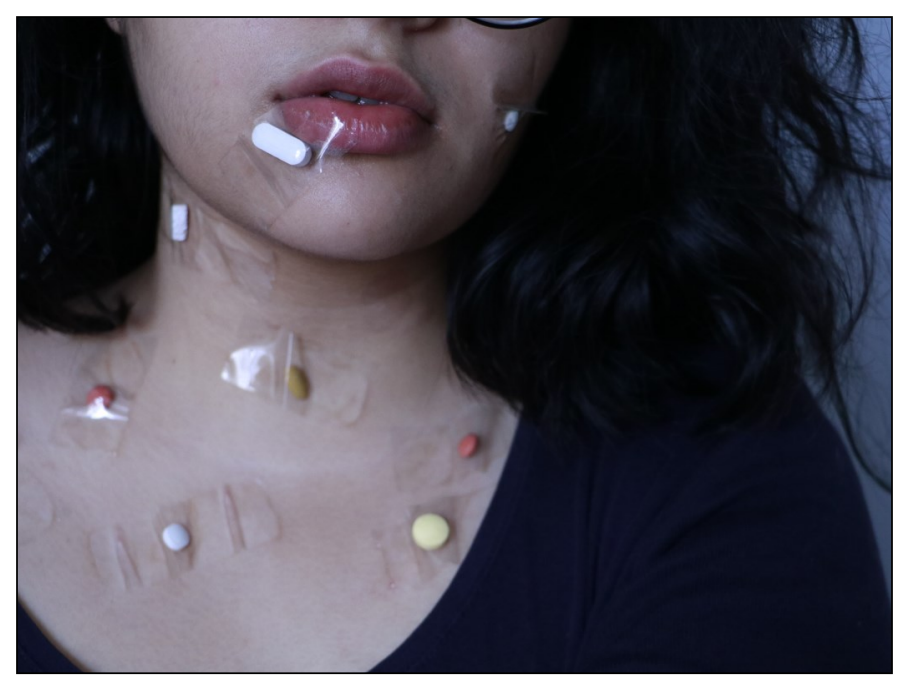

Figure 6. I'm scared. Scared that if I catch the virus, I won't be able to fight it off. WHO says those who already have underlying medical conditions are more susceptible to falling victim to this virus. I fall in that category. I live my life on medication. I'm always sick. I'm always in pain. And now, I can't even go out to get treatment because if I do, I might just die. So I stay at home. And take one pill. I take another pill. Then another. Another. One more. - Morsche

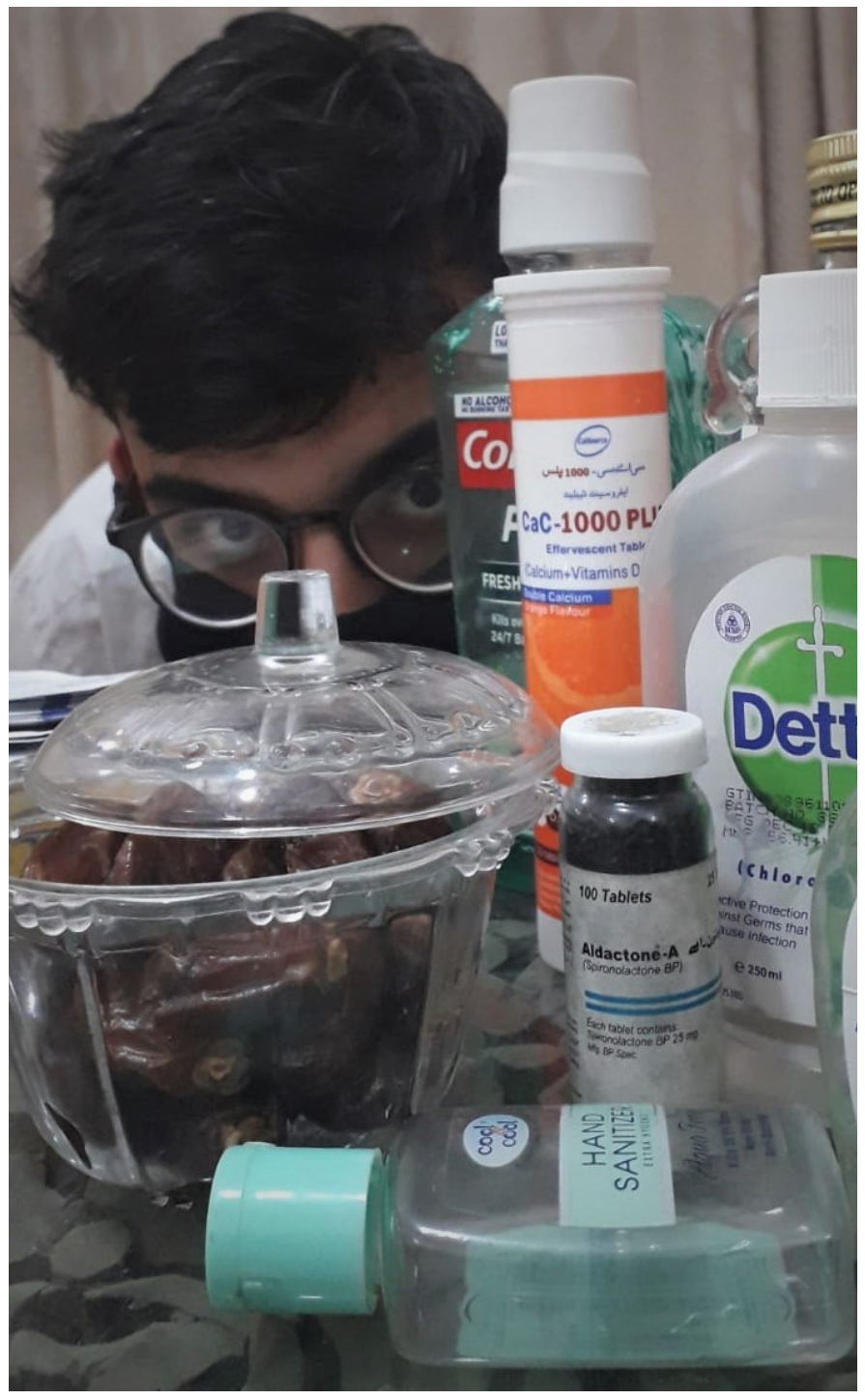

Figure 7. Fear and health. Sanitizers, Disinfectants, A/coholic Swabs, Soaps, Hand Gloves, Masks. Beware! You can catch it anytime, anywhere. Use them if you want to survive, cover yourself before you hit the ground. But listen, these are not enough... Wait. Do not forget what the nature has given you to combat it. Have dates, take few drops of olive oil, chew black cumin seeds, and increase your intake of citrus fruits. Believe me, this may help. Just use them as your shield and you might survive.

Visiting the supermarket after shutting myself at home for twelve days was a sigh of relief. I asked my dad not to turn on the vehicle's AC. I wanted to take fresh air with the window rolled down. Empty roads-in Karachi- a sight I used to have at the iftar time during Ramzan. However, that was a normal Tuesday noon. As l entered the super mart the guard allowed the entrance to only those wearing masks. They were not using the metal detector this time. They were searching for something else and the tech seemed unhandy. My temperature got checked. I was allowed to proceed. 'Six feet away, on the marks only'. A man in all white costume repeated every few seconds. 'Sanitize your hands before you enter'. I started to pray for a safe return to home. Without the dry cough. - Hamza 


\section{Fear and anxiety}

Fear is an emotion that spikes up during times of uncertainty, and it is not surprising to see that most participants felt the emotion of 'fear'. However, the emotion manifested in unique ways. Whilst some feared the monotony of lockdown life, others feared the consequences of the pandemic. The eerie atmosphere created by the unusual silence also contributed to the factor of fear. Other aspects of fear included anxiety about job security and what the future would hold. As the pandemic has brought economies, businesses, and entire ways of life to a halt, there has been a rise in uncertainty regarding jobs, careers, and studies which has manifested in the form of anxiety. These are primary concerns for undergraduate students as this four-year journey is critical for both their future careers and life in general. Witnessing the world in such a turbulent situation has consequently impacted academic performance and created a lot of anxiety and fear amongst students (see Figure 8). Empirical studies indicate that this fear turns into acute anxiety for the potential work force, concluding that long term isolation and distress affect mental health and productivity (Mahmud, Talukder, and Rahman 2020, 8). A participant highlighted that since they were restricted in terms of their daily activities, they had more time to think

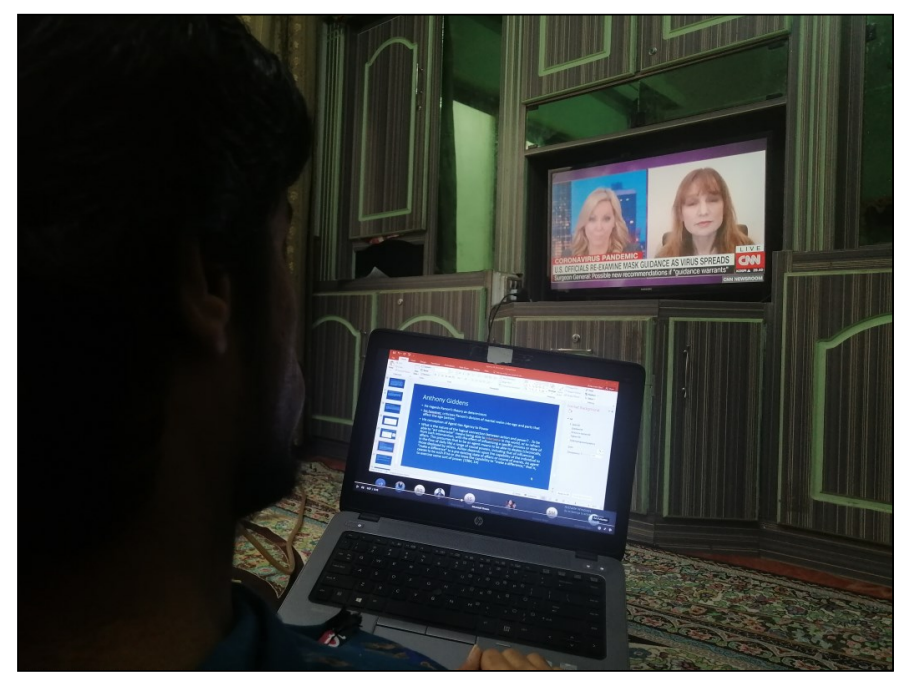

Figure 8. Fear, Anxiety and Uncertainty. In a time where anxiety and fear have clouded over us because of the Covid-19, students despite their persistent efforts to focus on their academics, fail to do so. In this picture a student who is trying to concentrate on his university assignment, has failed to ignore the drastic and severe cases of covid19 shown on the news channel. This picture shows how most of the students are in the state anxiety, fear, and uncertainty. - Nabeel about the deeper meanings of life, which, without finding answers, led to an endless spiral of anxiety and frustration. In terms of health-specific fear, there was also a fear of the health effects associated with the virus itself which has been discussed above.

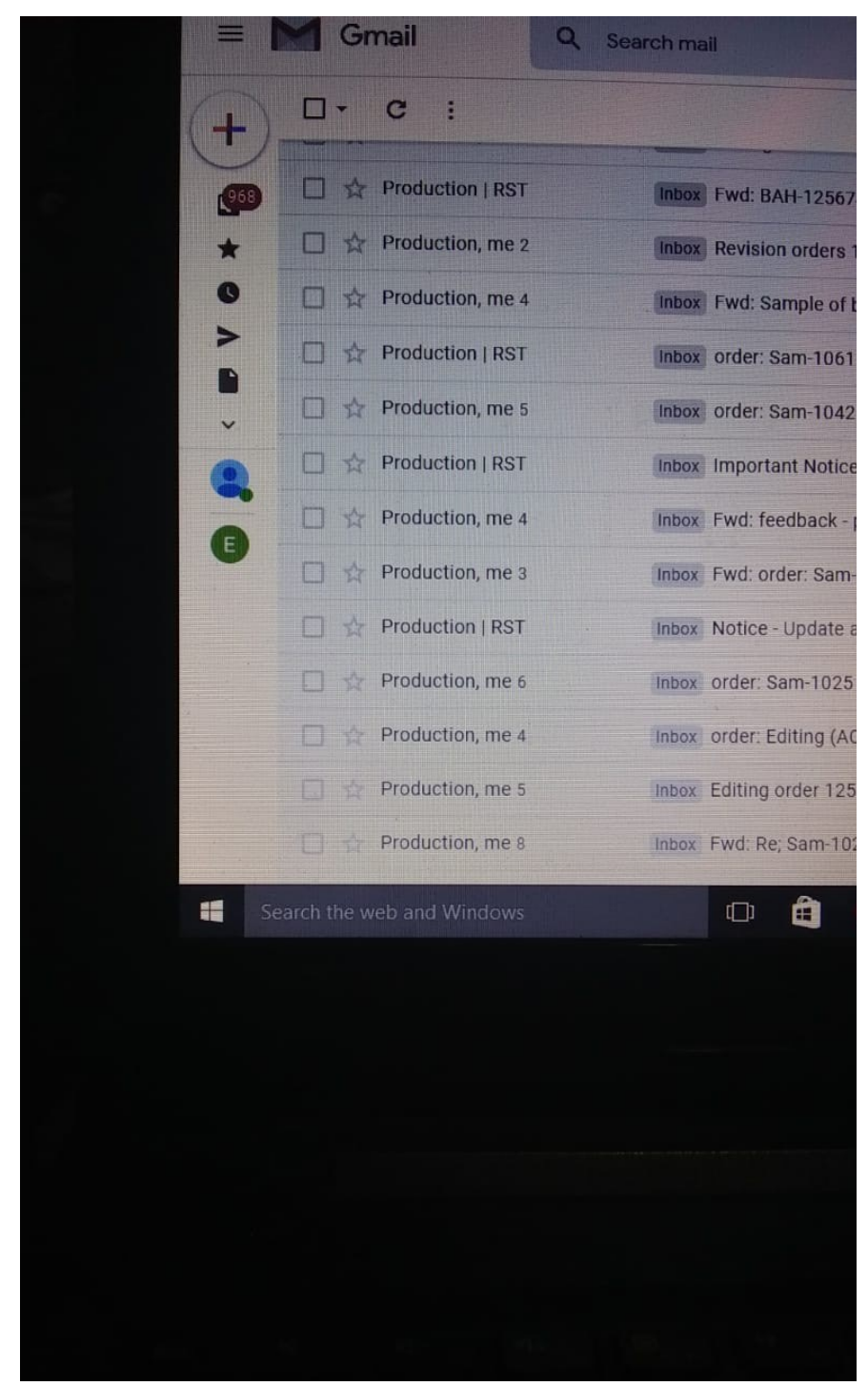

Figure 9. When your manager doesn't believe that you are actually having online classes as no other university is doing so. Hence, keep pressurizing with added assignments. Not to mention, with salary deduction threats and job loss. - Azka

\section{Study settings}

One of the biggest changes in students' lives has been in their study settings. Many participants highlighted this theme in some way or another. Some showed their study areas to portray how they were constantly sitting in the same setting, whereas on campus they would be moving around visiting friends, faculty, and other classes. Thus, there is a sense of laziness, lack of creativity, and unproductivity that 
follows from such a study space. Another participant showed an image of their bedside area which was overflowing with wires since everything was now digital and they constantly needed those wires for some device or another which left their space looking messy. Other participants also portrayed the informality of the setting, which was shown by eating food or checking the phone during a class (see Figure 10). This provides a contrast to how formal study settings restrict students' activities and aid them in disciplining themselves. There was also a sense of frustration that accompanied the new study setting since not all participants had a stable internet connection (see Figure 11), a secluded area to study, or a personal device

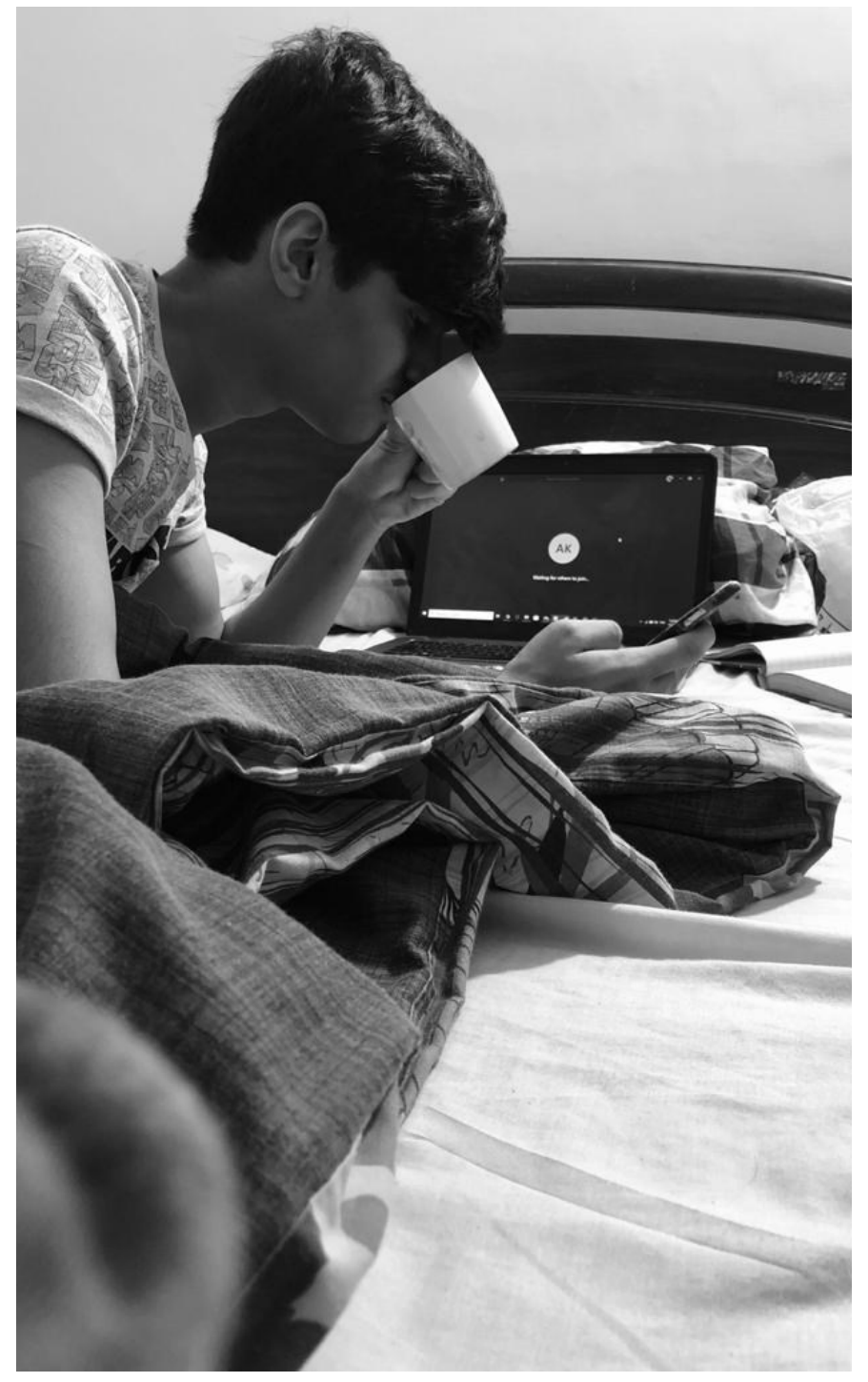

Figure 10. Or maybe the mornings are the same but instead a bit more relaxed and easy-going, where we have the liberty to attend the classes without paying much attention.

A live and guilty depiction of online classes at home. - Areeb through which they could attend classes. All these problems contribute towards the worries of students and their academic performance. This also highlights how some students are at an unfair disadvantage to students who do not face such issues at home.

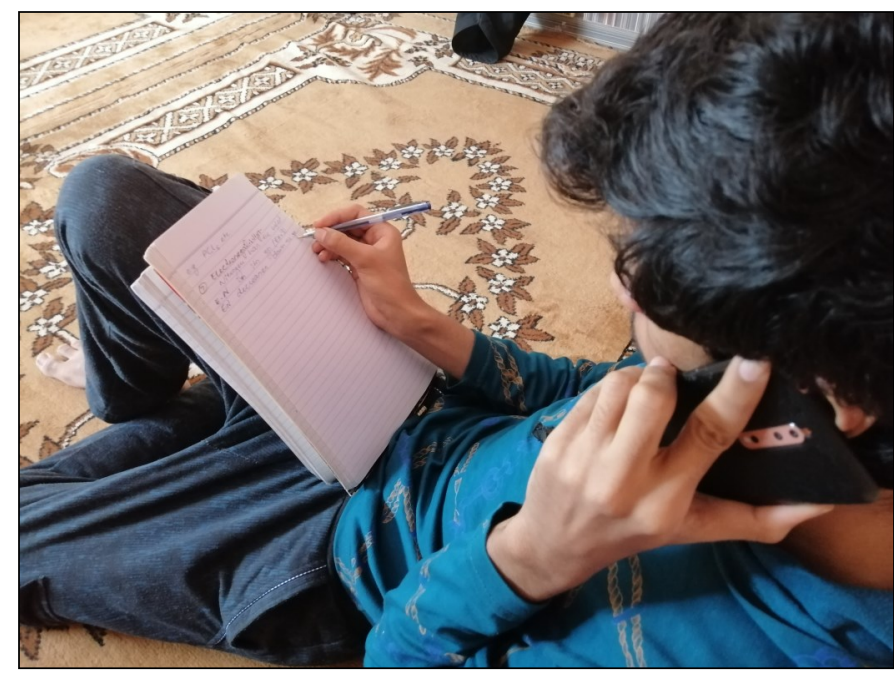

Figure 11. Accessibility to Internet. While some universities have announced to go online, students living in rural areas or with no internet connection have found different ways to catch up with their classes. In this picture, a student is calling his friend to ask and make notes of what his professor has taught that day. - Nabeel

\section{Relationships}

Since the dynamics of every aspect of life have changed, so have the dynamics of relationships. Relationships here are broadly categorized as any human-to-human relation. The lockdown has affected some relationships negatively but simultaneously it has also benefitted other relationships. This theme was extremely diverse in the meanings that different participants expressed through it, primarily because relationships are subjective and personal. "Humans are social animals and naturally live in groups for solidarity and support" (Corvo and De Caro 2020, S248). There was an element of loneliness expressed through the photos as social interaction beyond the household has curbed due to the lockdown. "The friendship ties (community spirit) have been affected too because the lockdown rules imposed allowed for seeing and having relationships with only and exclusively the individuals who live in the same house" (Corvo and De Caro 2020, S247). A participant symbolized the absence of physical touch through a lipstick stain, highlighting the importance of physical interaction and the relations associated with it (see Figure 14). Due 
to the lockdown, cherished weekly family gatherings at a participant's house can also suddenly no longer happen. Although they meet each other virtually, physical interaction is not possible and that is what the participant misses. One participant pointed out that they were not able to spend time with their family members as education continued online and they had to be sitting alone in a room with their door shut to attend their classes which made them feel claustrophobic (see Figure 13). However, at the same time many other participants also highlighted that the quarantine has allowed them to strengthen their relationship with the members of the household, such as their parents and siblings, by having more time to bond with them and finding comfort in their company.

Education has also been impacted by the relationship with household members. Many students in Karachi live in a joint family system, the extended family as constituted predominantly from the paternal descent line, which makes it difficult to focus on studies, especially when the student does not have a secluded/private space to study which consequently affects academic performance. A participant showed this through a cousin playing a board game while he tried to study in the same room.

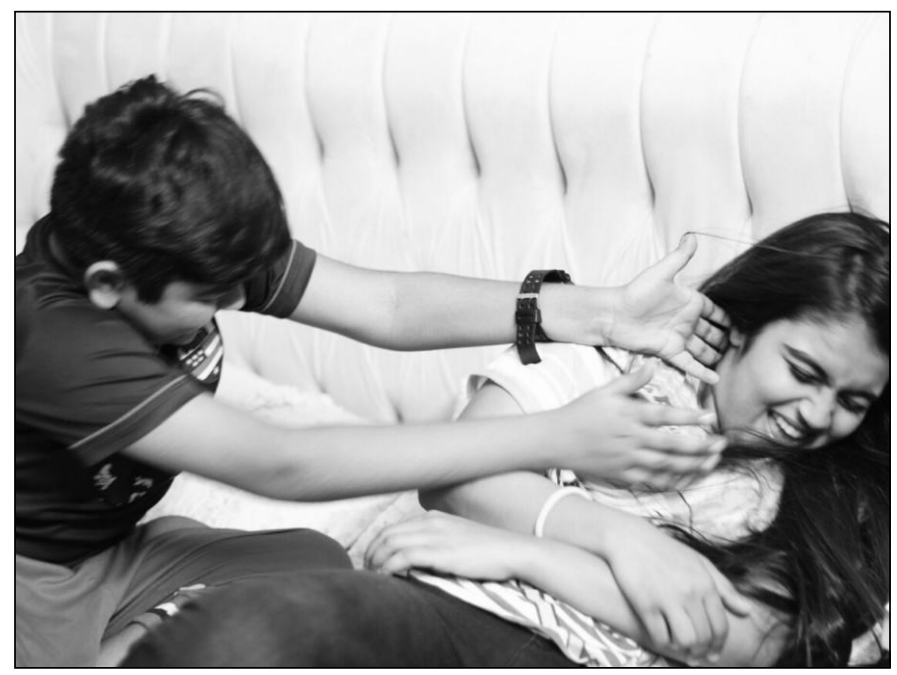

Figure 12. Quarantine was meant to provide a break from the chaos of life but very little did I know that it will break the silence between us siblings and bring back the giggles, otherwise lost amidst the hustles of life! - Areeb

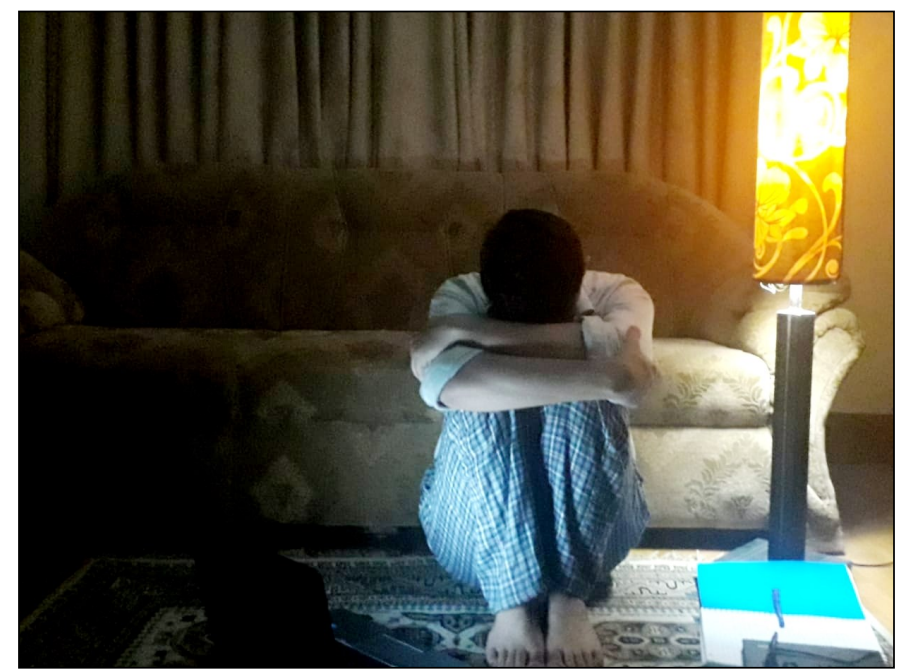

Figure 13. It's been almost a month since I have met my friends. We do talk via online channels but that special feel is absent. The idea of having the entire world at one's disposal with a laptop beside just fades into the darkness of loneliness and confinement. - Hamza

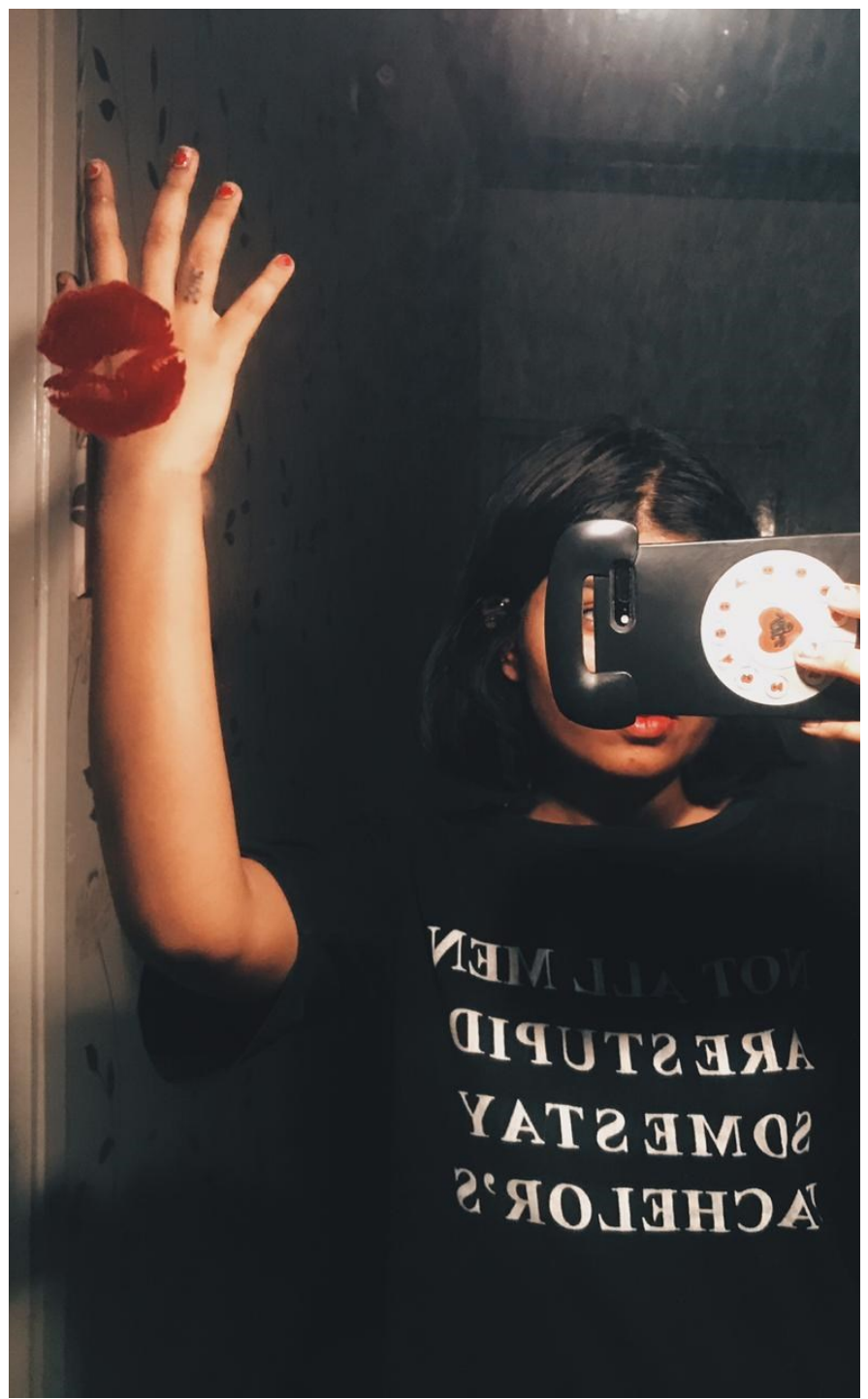

Figure 14. This is just about missing my friends and being their presence. Physical touch is my love language and I miss my friend' hands all the time. This was a recreation of that feeling. - Rumaysa 


\section{Time holds a different meaning}

The experience of time has changed for many people, while some people have found that they can now spend time on self-care and hobbies, others also find that boredom has led them to a depressed state of mind (Banerjee and Rai 2020). However, most participants in this study shared that the free time now at hand was utilized in positive ways. A study of the French population conducted by Droit-Volet et al. (2020) explores how people experience time during the lockdown and its link to the general emotional state of a person. It shows that for most people surveyed, time had slowed down and simultaneously there was an increase in stress (6). However, they conclude that there was no link between the perception of time with stress levels rather it was the "emotional experience of everyday life" (10) which affected the experience of time. Increasingly, in our study it was observed that participants were using the lockdown as a time to be able to slow down in their lives, which was symbolized through casually sipping tea, or just even having the time to make tea itself, which they previously did not have. It was also observed that some participants were investing time doing things which they always wanted to do but did not have the time for before, such as learning how to cook and bake.

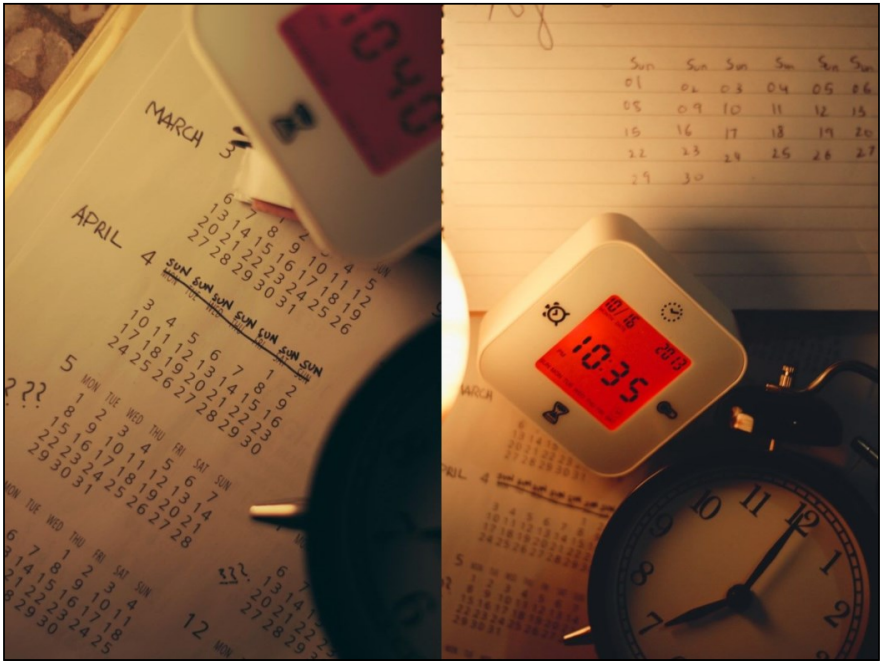

Figure 15. What is time?

Aunt: You guys have cooked bhindi on a Sunday?

Me: Oh, is it a Sunday today? *scrolls phone to check the date*

Aunt: Yeah, I've cooked Chicken Biryani since we ran out of mutton.

Me: Oh! I've completely lost track of days! - Neha

This once again highlights how life has taken a pause and is slowing down by providing us time to reflect on our lives and its purpose. Since the understanding of time greatly relies upon work schedules, a participant pointed towards how there was no longer a distinction between the days of the week. Usually Sundays are preserved for cooking something special for the family but that is no longer the case since everybody is always at home so special meals can be cooked at any time of the week (see Figure 15). There is no distinction of days

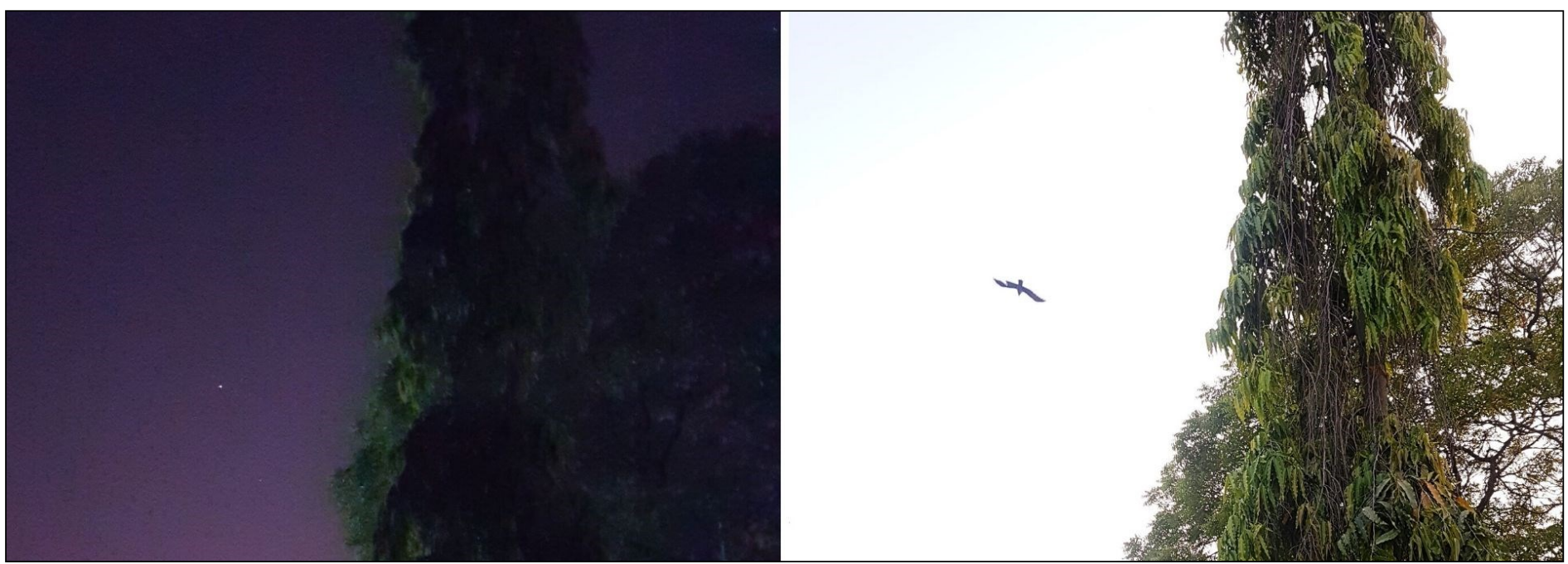

Figure 16. One thing that really stands out during this lockdown is the silence that surrounds us. Despite working from home, talking to family and friends and loved ones, there is a trail of endless silence that follows us. When we stop and listen to it, it shows us the shifts of time that we often take for granted when running around making a 'life' for ourselves.

I find that there is peace in the darkness of the night, as I feel it taking me completely within its solemn being, coaxing me to surrender to its serenity. Later, that embrace is ruffled by the calls of birds at the first sight of dawn. Their calls resembling the crowd that all of us are accustomed to. A crowd that we are a part of or rather try and be a part of. Even now the mornings seem rushed as if everything around us pushes us towards a 'purpose' whatever that might be, that is if there is such a thing as purpose. - Mishal 
otherwise either, since we no longer have specific days associated with particular tasks, such as relaxing on a weekend or going to work on a Monday. A participant highlighted how time went on, but our lives remained monotonous, this was shown by contrasting two images of the sky, one taken at night and the other taken during the day (see Figure 16). Thus, symbolizing how the passage of time still went on as usual whilst our lives had become stuck in the same physical space. For some participants, life had become even more busy as they were loaded with more and more work by employers, since being at home has created this illusion of having more 'free time' at hand.

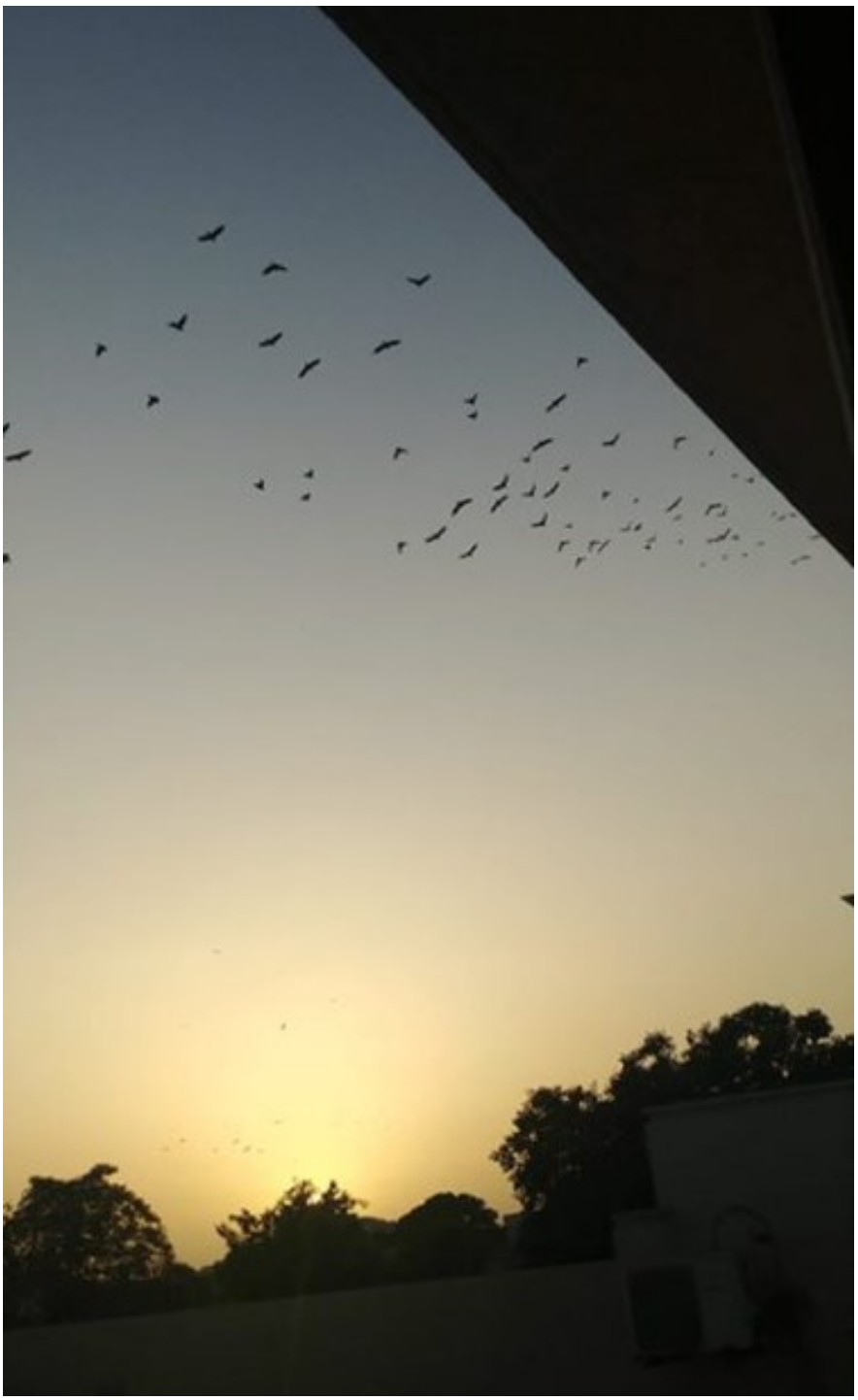

Figure 17. View from my tea session with flock of birds passing through during sunset. - Aqib

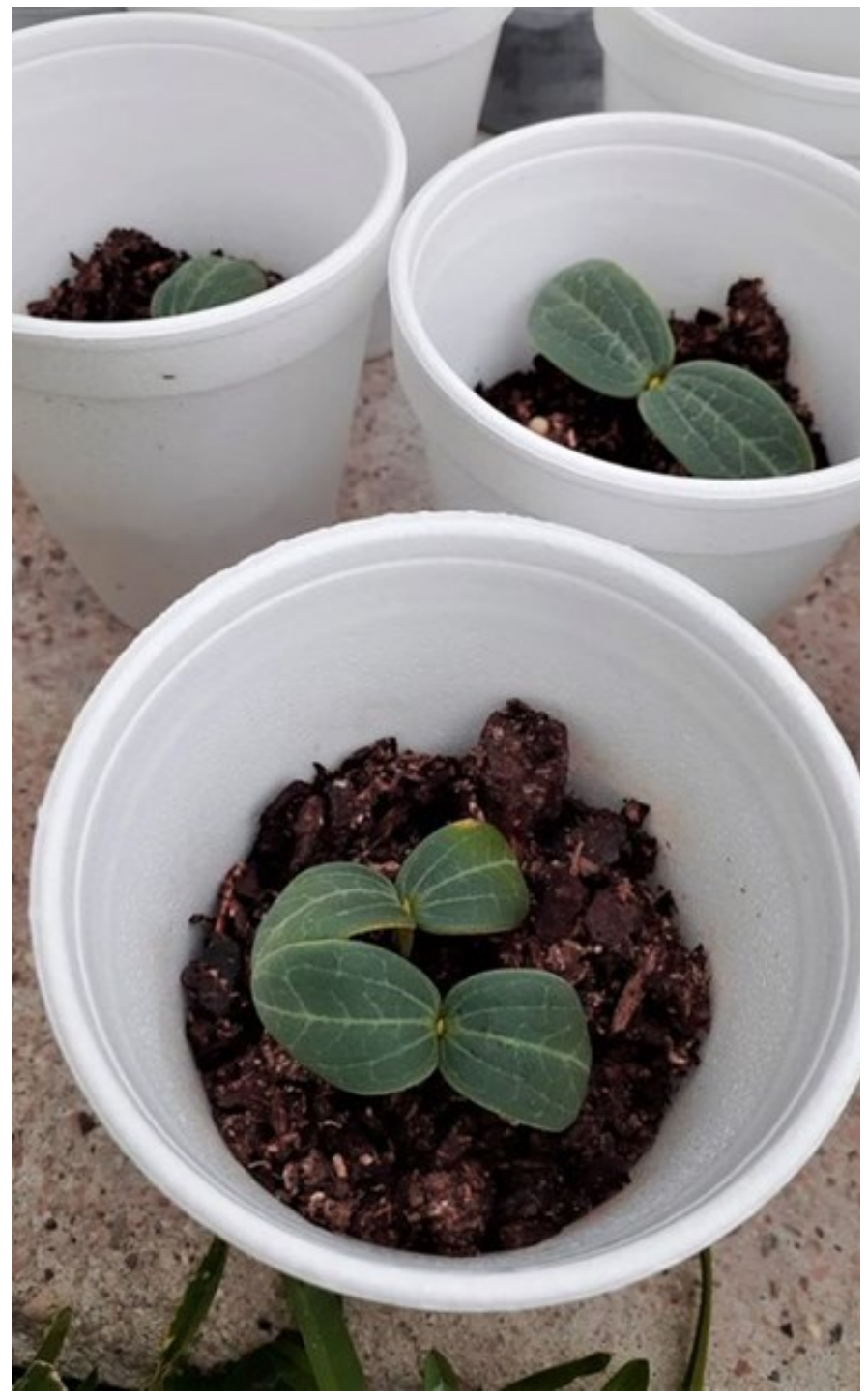

Figure 18. In the days of despair, when the time halted to fly, when one began to run away from the screen... I found solace in holding the shovel, in feeling the grains of soil. I waited not for my assignment grades but for something extraordinary to emerge. I was not hopeful though, the surrounding conditioned me to think me that way. It took two weeks and it appeared. It is tiny but it is growing. It is feeble but it gives strength. - Hamza

\section{Hope}

One of the other prevalent themes was that of hope. Since hope is not tangible, there were various symbols in the surroundings through which people chose to represent it. There were some participants who chose the sky as a symbol of hope (see Figure 17) whilst another participant chose to symbolize hope through the growth of seedlings (see Figure 18). Seeds are sowed in the darkness of the soil beyond which we cannot see, but soon the seeds begin to germinate and emerge out of the soil like a ray of hope, providing a sense of both achievement and strength. As the night is followed by day, the darkness is also necessarily 
followed by light, and so, light has come to symbolize hope - an element seen across multiple photographs, often portrayed by looking up to the sky. Hope was also sought through God and religious devotion, by putting trust in Him and having faith in His power and believing that things will become better soon.

\section{Coping mechanisms}

Being humans, we all search for sanity by retaining some sense of normality. This may come from various aspects like spending time with the family, or carrying out a hobby like cooking, or devoting time to self-care. Overwhelmingly participants tried to keep themselves busy with cooking/baking (see Figure 19). Aymerich-Franch (2020) conducted a study to observe the change in habitual routines of individuals during the lockdown and found that "Cooking and baking also showed an important increase, as $54.3 \%$ of the sample

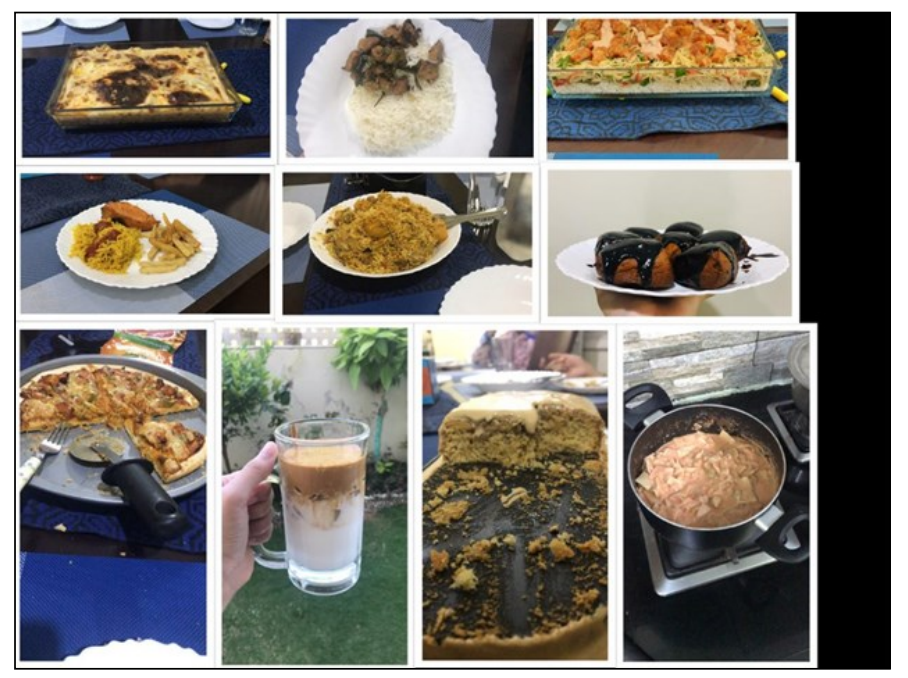

Figure 19. This picture describes my quarantine life quite aptly. These are a few pictures of the dishes I have made since this quarantine has started. I don't exactly know how I feel about this, though. I mean, I do like to cook sometimes when I am free, which I never was during school. However, now I feel I have been doing it just for the sake of having something to do. This picture is a representation of an effort from my side to keep myself occupied in an otherwise chaotic world. To keep me from thinking about the pandemic. I do this to tire myself enough during the day, so I sleep at night in seconds with no time to think about how long this quarantine will last and for how long we will have to stay inside. I feel the experience with this quarantine of my family members has genuinely gotten better as they get to eat something new and different almost every day. I, on the other hand, am yet to figure out how I feel about my cooking spree. However, this spree also took a recent hit day before yesterday when I realized that it is unfair. It is unjust that people out there are starving while I am out here making different food items, having three dishes on my table. While / sit there being confused between what I should try first, people outside the walls of my house wish for a single meal. - Sara cooked more often and 51.6\% baked more often" (6). It is an activity that requires constant attention and thus keeps the mind occupied whilst also being rewarding. It also shows the importance that food plays in our lives, it brings joy, but it is also a source of literal and figurative nourishment, both desperately needed during these times. Other participants also spent time rediscovering old magazines, playing guitar, and playing board games. There was also more time to focus on self-care in the form of personal grooming, which involved makeup and skincare. Caffeine, either in the form of tea or coffee was also something that participants used to cope up with the current situation (see Figure 20). Overall, most of the participants did try to do something on their part to keep themselves occupied and help them cope up with the current situation.

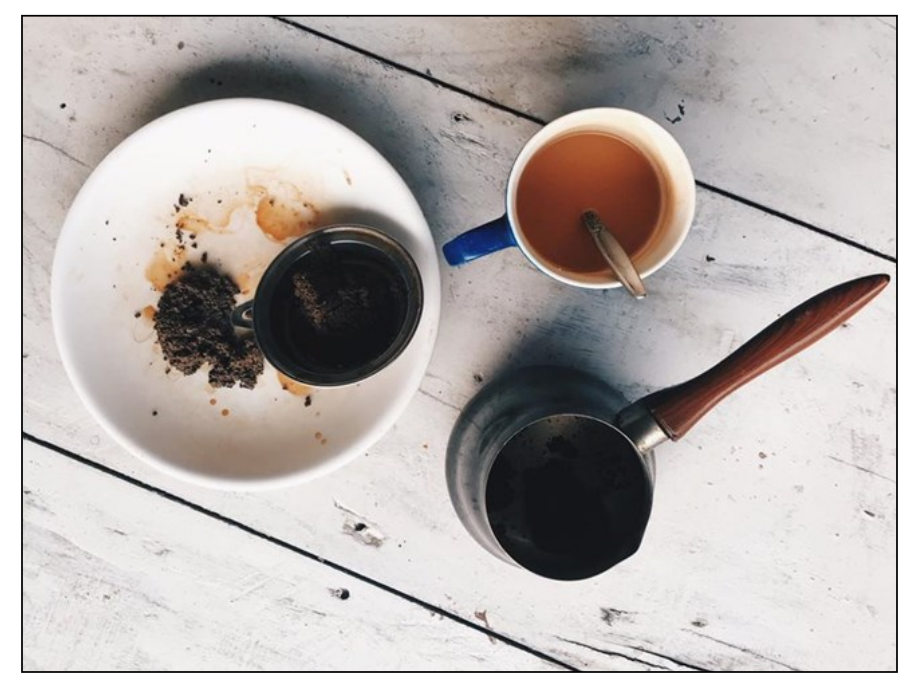

Figure 20. The small tea pot sieve and cup show repetition. I love tea and I'm a heavy tea drinker but I have been consuming too much of it just to feel something. - Rumaysa

\section{Finding solace in nature}

Following from the theme of hope and coping mechanisms, nature provides a source of comfort for many participants as well. A study conducted on the role of the environment in recovery from alcoholism also showed that many participants found comfort in different elements of nature, mostly features of the natural environment (Shortt, Rhynas, and Holloway 2017, 150). Some individuals took pictures of the sky or pictures of a landscape. Whilst some other participants "found comfort in tending to house and garden plants" (153). In the urban setting of Pakistan, many participants tried to find some sort of calmness by whatever aspects of nature were accessible to them as 


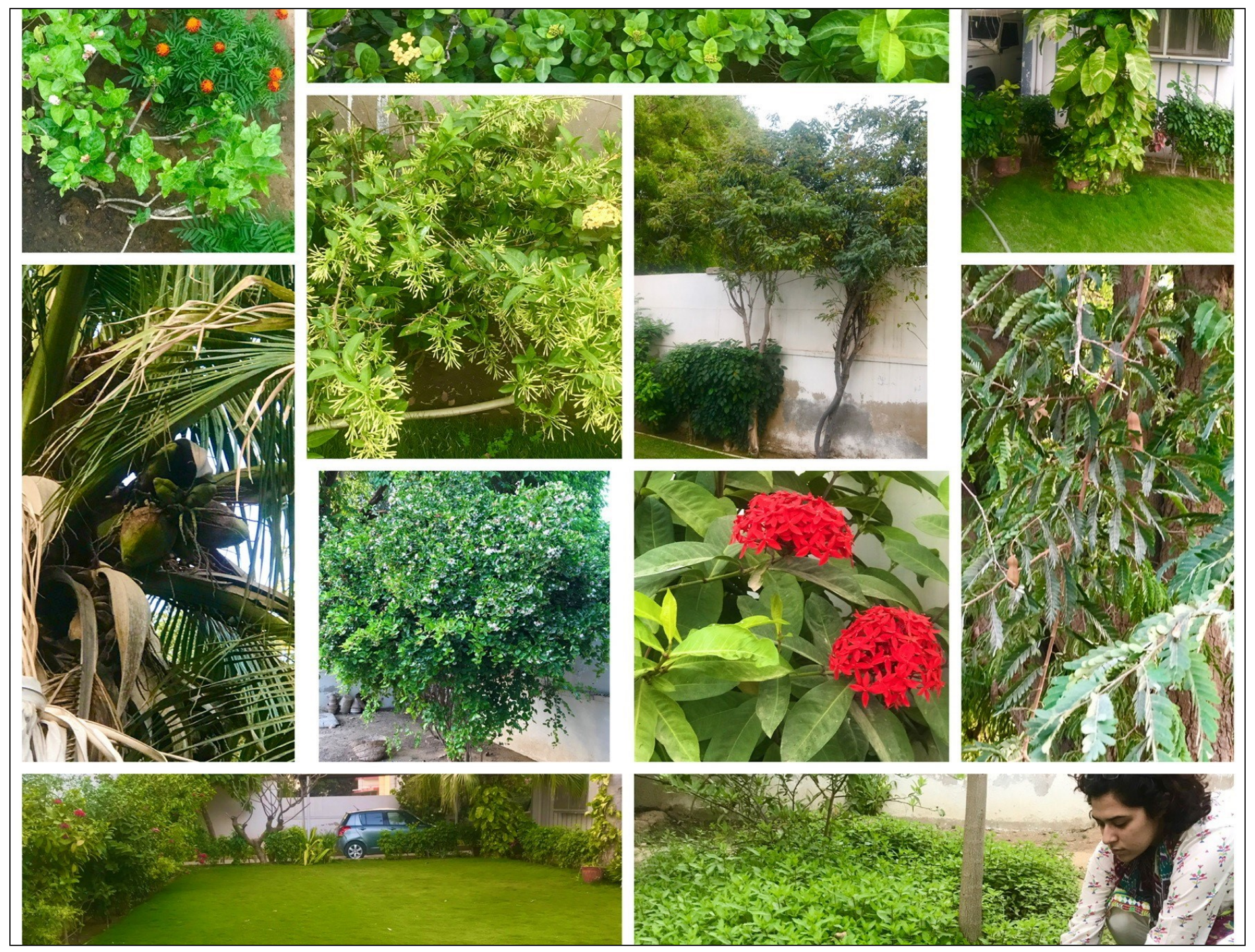

Figure 21. I have really started to appreciate my garden much more these past few days. Being the daughter of two environmentalists I am most comfortable around greenery. - Mishal

well. We saw how birds, animals, and plants provided peace of mind and brought serenity into their chaotic lives. Many participants sought to express this through their own pets, such as cats and parrots. Others sought to find calmness through the birds flying across the sky or flowers that were growing in their balcony. There was also an element of finding comfort in the idea that nature was finally having time to replenish itself, as all human activities have been brought to a bare minimum. Another participant highlighted finding comfort by tending to the plants in her garden and the greenery in it, which also helps her stay sane during these complex times (see Figure 21). Thus, a recurring theme of nature providing a sense of calmness is prevalent across many photographs which reflects upon the "traditional notions of healing in the natural" (150) and using it as a medium to recover and retain sanity.

Participants had various responses to the experience of taking these images. A student mentioned finding it difficult to take photographs of their experience as they found it emotionally draining to think about the lockdown and the impact that it had on them. Yet the photovoice assignment was also a good opportunity for students who do not like to speak up in class to contribute to the learning process. This highlights the importance of having more than one mode of communication in qualitative research, which in our case was photography. The photography process also served as a medium for self-exploration and discovery, forcing us to think deeply about things that are only given attention at a surface level. 


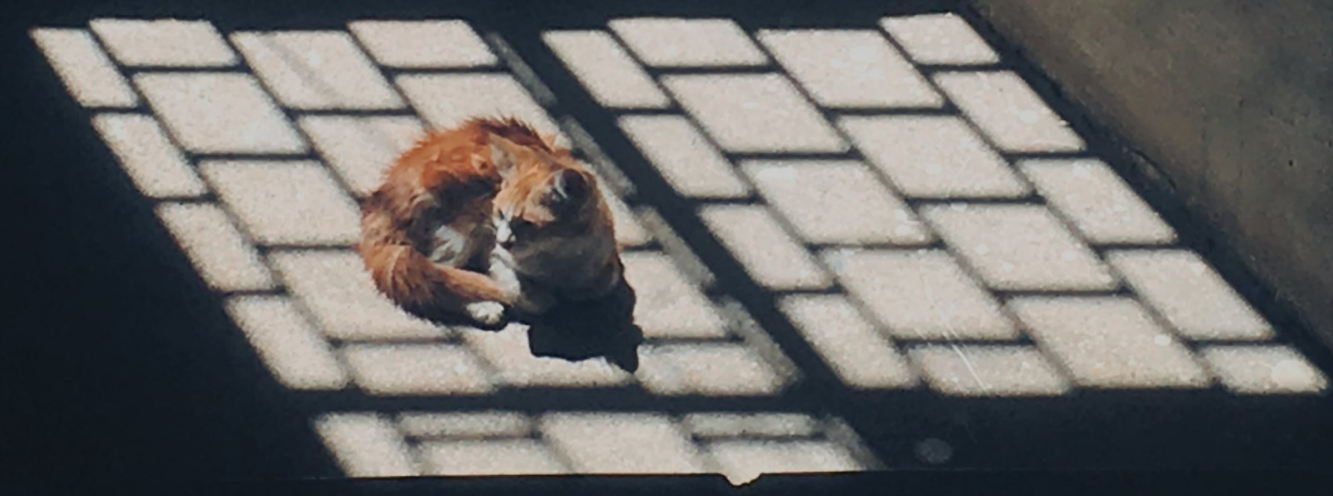

Figure 22. Calm in the storm. This was a photograph of a kitten taken right outside my main door on the staircase landing in my apartment. My class was about to begin but I did not want to leave this comforting and calming view (but with a heavy heart I had to head back inside). Covid-19 has for sure made our lives miserable but nature and other forms of life are probably having their best lives for once and that is just so warming to think of. - Neha

The photos highlight that the lives of students living in the lockdown have both positive and negative aspects: for some students it has been quite a difficult experience, whilst for others it has not been as difficult. The participants may also have experienced each of the above aspects differently; while some participants missed their friends or struggled with online education, others were glad to be able to bond and spend time with their family at home. Overwhelmingly, the students who chose to highlight their educational experience online showed that it was not productive and they either faced issues due to the lack of resources or in adapting to the new study settings. We also observe that almost all students are facing some sort of emotional and mental challenges during these difficult times, which is affecting all spheres of life including academic performance. A study of the impact of COVID-19 conducted among participants living in Spain notes that "the younger cohorts presented a larger negative effect on psychological well-being resulting from the lockdown" (Aymerich-Franch 2020, 9). Thus, it is important for the relevant authorities to take all these difficulties that students are facing into consideration whilst making any decisions pertaining to academic studies and supports or the lockdown in general. The findings also stress how real and important the emotional challenges of the pandemic are, which thus need to be addressed with sympathy and deep consideration. The findings can also be used as a reference for expectations that instructors have of students, 
which could be eased by changing the nature of assignments or relaxing deadlines. The photovoice method could also be taken up by other instructors as part of their course, as it allowed the participants to express themselves through a different medium of communication and also allowed for self-discovery.

\section{Conclusion}

This paper documented the lived experiences of students residing in urban Pakistan during a global health crisis through a participatory approach. Our study provided the undergraduate students with a platform to share their perspectives and insights on a major and rapid change in their lives. This paper categorized students' life under lockdown into major themes while analyzing their coping mechanisms, sources of hope and frustration, and their quest to find solace in the present circumstances.

With the purpose of the study also being pedagogical, this work presents how to teach qualitative research using participatory methods. Through self-exploration of context and lived experience, it shifted teaching strategy to make it relatable to students. The study further demonstrated to the participants how to conduct fieldwork in a restrained context. The research introduced the participants to PAR methodology and helped them realize the importance of inclusion in community-based research. It also ensured greater flexibility for our participants in terms of space and time, consequently giving them a platform to be innovative and creative. It prompted them to delve deeper into their feelings and experiences which helped to collect more elaborate information while empowering the participants as they directed the course of research.

It also demonstrated the value of community -based participatory research and the holistic results it produces while emphasizing the importance of context in social sciences research. The findings of this study could help managers of higher education in Pakistan and elsewhere to understand the psychological and academic problems faced by the population whose lives they shape. 


\section{Acknowledgements}

We would like to thank Dr. Shama Dossa for her endless support, guidance, and feedback, without which this study would have never been possible. We also extend our gratitude to all the contributors and participants of this study for their cooperation and active response. 


\section{References}

Ali, Noor. 2020. “Students Disappointed with Online Teaching System amid COVID-19." Daily Times, April 1, 2020. https:// dailytimes.com.pk/587446/students-disappointed-with-onlineteaching-system-amid-covid-19/.

Aymerich-Franch, Laura. 2020. “COVID-19 Lockdown: impact on psychological well-being and relationship to habit and routine modifications." PsyArXiv, May 14, 2020. doi:10.31234/ osf.io/9vm7r.

Banerjee, Debanjan, and Mayank Rai. 2020. "Social Isolation in Covid19: The Impact of Loneliness." International Journal of Social Psychiatry66 (6) (September 2020): 525-27. https:// doi.org/10.1177/0020764020922269.

Bergh, Bethney. 2009. “A Qualitative Study of School Lockdown Procedures and Teachers' Ability to Conduct and Implement Them at the Classroom Level." PhD diss., Western Michigan University. https://scholarworks.wmich.edu/dissertations/648.

Burgess, Simon, and Hans Henrik Sievertsen. 2020. "Schools, skills, and learning: The impact of COVID-19 on education." VoxEU CEPR, April 1, 2020. https://voxeu.org/article/impact-covid-19education.

Corvo, Elisabetta, and Walter De Caro. 2020. "COVID-19 and spontaneous singing to decrease loneliness, improve cohesion, and mental well-being: An Italian experience." Psychological Trauma: Theory, Research, Practice, and Policy12 (S1): S247S248. http://dx.doi.org/10.1037/tra0000838.

Dattilio, Frank M., and Arthur Freeman. 2007. "Introduction." In Cognitive-Behavioral Strategies in Crisis Intervention, edited by Frank M. Dattilio and Arthur Freeman, 1-21. 3rd ed. https:// www.guilford.com/excerpts/dattilio.pdf?t.

Droit-Volet, Sylvie, Sandrine Gil, Natalia Martinelli, Nicolas Andant, Maélys Clinchamps, Lénise Parreira, Karine Rouffiac, Michaël Dambrun, Pascal Huguet, Benoît Dubuis, Bruno Pereira, JeanBaptiste Bouillon, and Frederic Dutheil. 2020. "Time and Covid-19 stress in the lockdown situation: Time Free, Dying of Boredom and Sadness." PsyArXiv, May 1, 2020. doi:10.31234/osf.io/efdq5.

Duncan-Andrade, Jeffrey M., and Ernest Morrell. 2008. "Youth

Participatory Action Research as Critical Pedagogy."

Counterpoints 285: 105-31. http://www.jstor.org/

stable/42979872. 
Franco, Manuel. 2020. "Urban Health and Coronavirus Crisis: In Confinement, Inequality Is Magnified." Accessed February 28, 2020. https://www.agenciasinc.es/en/Opinion/Urban-health-andcoronavirus-crisis-in-confinement-inequality-is-magnified\#top.

Goldstein, Dana, Adam Popescu, and Nikole Hannah-Jones. 2020. “As School Moves Online, Many Students Stay Logged Out." The New York Times, April 8, 2020. https://www.nytimes.com/2020/04/06/ us/coronavirus-schools-attendance-absent.html.

Jung, Insung, Masayuki Kudo, and Sook-Kyoung Choi. 2012. "Stress in Japanese learners engaged in online collaborative learning in English." British Journal of Educational Technology 43 (6): 10161029. https://doi.org/https://doi.org/10.1111/j.14678535.2011.01271.x.

Lazarevic, Bojan, and David Bentz. 2020. "Student Perception of Stress in Online and Face-to-Face Learning: The Exploration of Stress Determinants." American Journal of Distance Education: 114. https://doi.org/10.1080/08923647.2020.1748491.

LeBlanc, Paul. 2020. “COVID-19 has thrust universities into online learning -how should they adapt?" Brookings, March 30, 2020. https://www.brookings.edu/blog/education-plusdevelopment/2020/03/30/covid-19-has-thrust-universities-intoonline-learning $\square$-how-should-they-adapt/.

Lima, Carlos Kennedy Tavares, Poliana Moreira de Medeiros Carvalho, Igor de Araújo Araruna Silva Lima, José Victor Alexandre de Oliveira Nunes, Jeferson Steves Saraiva, Ricardo Inácio de Souza, Claúdio Gleidiston Lima da Silva, and Modesto Leite Rolim Neto. 2020. "The emotional impact of Coronavirus 2019-nCoV (new Coronavirus disease)." Psychiatry Research 287: 112915. https://doi.org/https://doi.org/10.1016/j.psychres.2020.112915.

Mahmud, Md. Shahed, Mesbah Uddin Talukder, and Sk. Mahrufur Rahman. 2020. “Does 'Fear of COVID-19' Trigger Future Career Anxiety? An Empirical Investigation Considering Depression from COVID-19 as a Mediator." International Journal of Social Psychiatry(online first). https:// doi.org/10.1177/0020764020935488. 
Necheles, Jonathan W., Emily Q. Chung, Jennifer Hawes-Dawson,

Gery Wayne Ryan, Shield B. Williams, Heidi N. Holmes, Kenneth B. Wells, Mary E. Vaiana, and Mark A. Schuster. 2007. “The Teen Photovoice Project: A Pilot Study to Promote Health through Advocacy." Progress in Community Health Partnerships: Research, Education, and Action 1 (3): 221-29. https:// doi.org/10.1353/cpr.2007.0027.

O’Reilly, Kathleen M., Megan Auzenbergs, Yalda Jafari, Yang Liu, Stefan Flasche, and Rachel Lowe. 2020. “Effective transmission across the globe: the role of climate in COVID-19 mitigation strategies." The Lancet Planetary Health 4 (5): e172. https:// doi.org/10.1016/S2542-5196(20)30106-6.

Pan, Haimin. 2020. "A Glimpse of University Students' Family Life Amidst the COVID-19 Virus." Journal of Loss and Trauma 25 (6-7): 594-597. https://doi.org/10.1080/15325024.2020.1750194.

Rashid, Ammar. 2019. "If student unions are bad for education, why are our controlled campuses ranked among the worst in the world?" Prism, November 29, 2019. https://www.dawn.com/ news/1519162.

Rehman, M. Muneebur. 2020. "Online education in Pakistan in COVID -19 era | Daily Times." Daily Times, April 23, 2020. https:// dailytimes.com.pk/600452/online-education-in-pakistan-in-covid19-era/.

Ronzi, Sara, Daniel Pope, Lois Orton, and Nigel Bruce. 2016. “Using photovoice methods to explore older people's perceptions of respect and social inclusion in cities: Opportunities, challenges and solutions." SSM - Population Health 2 (December 2016): 732745. https://doi.org/https://doi.org/10.1016/j.ssmph.2016.09.004.

Rose-Redwood, Reuben, Rob Kitchin, Elia Apostolopoulou, Lauren Rickards, Tyler Blackman, Jeremy Crampton, Ugo Rossi, and Michelle Buckley. 2020. "Geographies of the COVID-19 Pandemic." Dialogues in Human Geography 10 (2): 97-106. https:// doi.org/10.1177/2043820620936050.

Shortt, Niamk K., Sarah J. Rhynas, and Aisha Holloway. 2017. “Place and recovery from alcohol dependence: A journey through photovoice." Health and Place 47 (September 2017): 147-55. http://dx.doi.org/10.1016/j.healthplace.2017.08.008.

Siddiqi, Soufia A. 2020. "Covid-19 education response." The News International, April 18, 2020. https://www.thenews.com.pk/ print/645803-covid-19-education-response. 
Strack, Robert W., Cathleen Magill, and Kara McDonagh. 2004. "Engaging Youth through Photovoice." Health Promotion Practice 5 (1): 49-58. https://doi.org/10.1177/1524839903258015.

Taylor, Steven, and Gordon J. G. Asmundson. 2020. “Life in a postpandemic world: What to expect of anxiety-related conditions and their treatment." Journal of Anxiety Disorders 72: article 102231. https://doi.org/https://doi.org/10.1016/ j.janxdis.2020.102231.

Tedrick Parikh, Sara J., and Carrie A. Wachter Morris. 2011. "Integrating Crisis Theory and Individual Psychology: An Application and Case Study." Journal of Individual Psychology 67 (4): 364-79.

The Urban Resource Centre, Karachi, Arif Hasan, and Mansoor Raza. 2015. "Responding to the transport crisis in Karachi." International Institute for Environment and Development Working Paper. IIED, London. http://pubs.iied.org/10733IIED.

Voegele, Juergen. 2020. "Three imperatives to keep food moving in a time of fear and confusion." World Bank Blogs, April 3, 2020. https://blogs.worldbank.org/voices/three-imperatives-keep-foodmoving-time-fear-and-confusion.

Wang, Caroline, and Mary A. Burris. 1997. "Photovoice: concept, methodology, and use for participatory needs assessment." Health Education \& Behavior24 (3): 369-387. https:// doi.org/10.1177/109019819702400309. 